\title{
Original Research Paper \\ ETIOLOGICAL AND CLINICAL PROFILE OF CASES OF CHRONIC LEG ULCERS ADMITTED IN TERTIARY CARE HOSPITAL OF TELANGANA
} General Surgery

\author{
Dr.mohd Abdul \\ Rehman* \\ Assistant Professor, Department of General surgery, Osmania Medical \\ college, Hyderabad, Telangana. *Corresponding Author
}

ABSTRACT Clinical study of Chronic leg ulcer (CLU) was carried out at local Telangana tertiary hospital revealed certain important data. Incidence of CLU were more common in above $51 \mathrm{yrs}(45 \%)$, in males $(72 \%)$ and in diabetics (34\%). Followed by venous (26\%), traumatic (16\%), arterial ( $9 \%)$, malignant $(5 \%)$, trophic $(3 \%)$ and other ulcers $(7 \%)$. Among 26 patients with varicose veins, 23 underwent surgery in form of Trendelenburg's operation, ligation and sub-fascial ligation. 2 patients with DVT underwent skin grafting. The mean time for healing was 16.4 days.

Among 34 diabetics, 30 were managed with regular dressings, antibiotics, slough excision and or debridement along with antidiabetics. Four patients underwent amputation and 12 underwent skin grafting which healed in average of 11 days. However, mean healing time was 21.5 days. With availability of lab investigations, wide range of antibiotics and with ever improving dressing material, there is certainly a great improvement in treatment of CLUs.

\section{KEYWORDS : Chronic Leg Ulcer, CLU, Diabetic Ulcers, Varicose Veins, Venous Ulcers}

\section{INTRODUCTION}

Chronic leg ulcer (CLU) also known as chronic lower limb ulcer is defined as an ulcer of the leg, which does not heal within a period of 6 weeks ${ }^{1}$. The prevalence of chronic leg ulcers is between $1.9 \%$ to $13.1 \%$ (shubhangi, 2013 \& Rahman et al, 2010 $)^{182}$

The incidence of ulceration is rising as a result of the ageing population and increased risk factors for atherosclerotic occlusion such as smoking, obesity, and diabetes ${ }^{1}$.

The problems of leg ulcer represent a wide spectrum of etiology, pathology, severity and morbidity. The main causes are venous valve insufficiency, lower extremity arterial disease and diabetes other causes include infections, vasculitis and skin malignancies. For a proper treatment of leg ulcers, it is important to know the differential diagnosis of leg ulceration.

CLU results in social distress and considerable healthcare and personal costs ${ }^{384}$. Since numerous factors lead to lower leg ulceration, it is essential to adopt an interdisciplinary approach to the systematic assessment of the patient in order to ascertain the pathogenesis, a definitive diagnosis, and optimal treatment required. A correct diagnosis is essential to avoid inappropriate treatment that may delay wound healing, cause deterioration of the wound, or harm the patient.

Treatment of these ulcers forms a challenging task as well. Therefore in present study we attempted to analyze the ulcers of the leg and foot in local Telangana population with clinical investigation and histopathological study of patients of chronic leg ulcers. And also to evaluate the various causes of chronic leg ulcers, various microorganisms grown in chronic leg ulcers and to evaluate the various methods of treatment of chronic leg ulcers.

\section{METHODOLOGY}

The material for this study was drawn from patients, presenting with chronic leg ulcers, to the General surgical OPD \& Emergency department of Kamineni institute of medical science, from September 2012 to October 2014. It is a prospective observational study. A total number of 100 cases were included patients of both sexes and age above 18 years. A detailed history was collected and a thorough systemic and local examination was carried out. Patients were subjected to relevant lab and radiological investigation, after taking their consent and ethical committee approval (number M125210176) from KIMS, Narketpally, Telangana.

\section{RESULTS:}

Incidence of leg ulcer in this study group was found to be maximum in the age group of 5 lyears \& above with male preponderance of $72 \%$. The youngest patient was 19 years old and the oldest was 75 vears (araph -1 ).

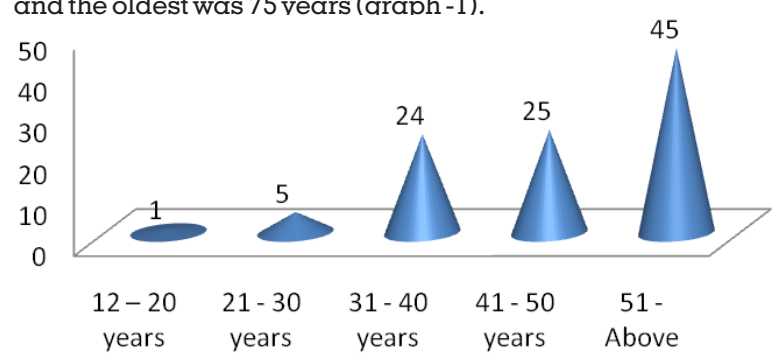

- Percentage

Graph -1: Age wise distribution of various types of chronic leg ulcers $(\mathrm{N}=100)$.

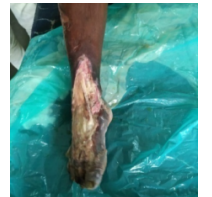

Figl:Diabetic Ulcer

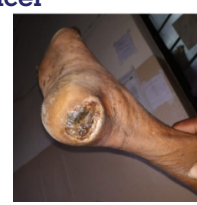

Fig 4: Trophic Ulcer

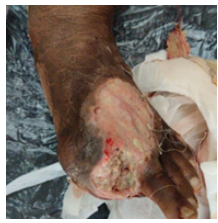

Fig 7: Arterial Ulcer

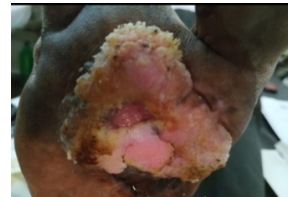

Fig2:Malignant Ulcer

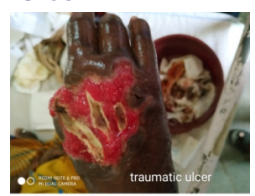

Fig 5: Traumatic Ulcer

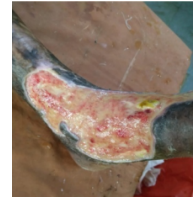

Fig 3: Venous Ulcer

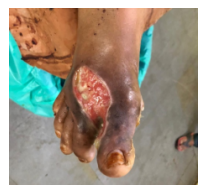

Fig 6:Ulcer due to snake bite
Among the 100 chronic leg ulcer (Fig 1 to 7) cases studied Diabetic ulcers were 34 cases, followed by venous 26 , traumatic 16, arterial 9, Malignant 5, trophic 3, and other cases of 7. 


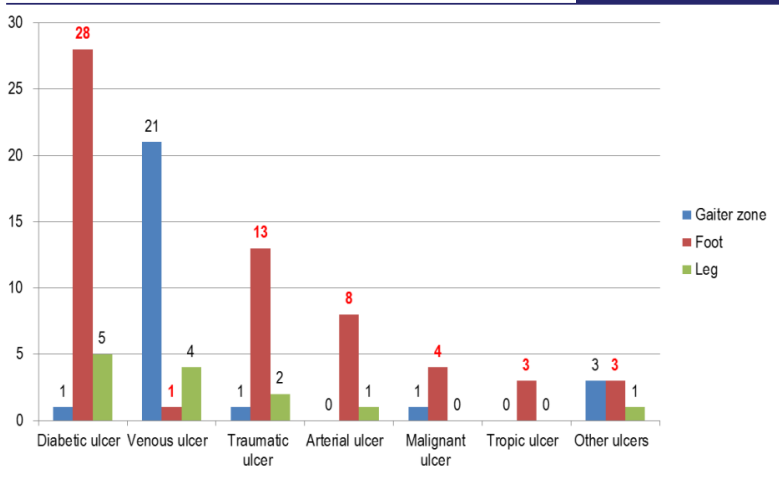

Graph - 2: Location of the ulcer according to its types $(\mathrm{N}=100)$

The venous ulcers occurred more commonly in their gaiter zone $(80.8 \%)$. Whereas arterial and diabetic ulcers occurred mainly in foot i.e., $88.8 \%$ and $82.4 \%$ respectively. About $80 \%$ of malignant ulcers occurred in the foot and rest of $20 \%$ in lower $1 / 3^{\text {rd }}$ of leg (graph - 2).

In present study number of patients suffering from diabetic ulcers was maximum in age group 51\& above accounting 20 cases $(59 \%)$. It is noted the diabetic ulcers were relatively common in male accounting for (65\%) and in females accounting for (35\%) with maximum no having ulcer on left limb accounting for 18 cases (53\%).

In present study venous Ulcers were found to be maximum in no. in $31-40$ yrs age group, accounting 13 cases (50\%). And males were commonly affected accounting for (81\%).

Arterial ulcers were found to be more common in age group 51 and above years ( 5 cases) and were found to be more common in Males 6 cases (66.7\%).

In our study the organisms isolated from the wounds were in following order staphylococcus 31\%, streptococcus 22\%, Klebsiella 14\%, Proteus 14\%, Pseudomonas 3\%, E.coli 3\% and no growth in $13 \%$ of cases. The various treatments used for our cases were shown in Table - 1 .

Table - 1: Showing mode of treatment $(\mathrm{N}=100)$.

\begin{tabular}{|c|l|}
\hline Number of cases & Mode of treatment \\
\hline 33 & Debridement + Daily dressings \\
\hline 31 & Debridement + Daily dressings + Split skin grafting \\
\hline 15 & Ligation + Stripping \\
\hline 8 & Trendelenberg's operation + ligation + stripping \\
\hline 7 & Below knee amputation + daily dressings \\
\hline 5 & Disarticulation of toes + daily dressings \\
\hline 1 & Wide excision+ daily dressings \\
\hline 100 & TOTAL \\
\hline
\end{tabular}

\section{DISCUSSION}

A total number of 100 patients were considered for this study. This group was a diversified one and included patients of both sexes and included chronic leg ulcers of more than 6 weeks duration.

The Rahman GA et al ${ }^{1}$. study shown the incidence of chronic leg ulcers are more common in two peak periods of age of presentation 30-39 and 50-69 years respectively. In present study chronic leg ulcers were found to be common in the age group above 51 years (45\%), and in 4l-50 age group (25\%) respectively. Youngest patient was 19 yrs and oldest patient was75 yrs of age.

According to Shubhangi V. Agale ${ }^{2}$, CLU are more in females and according to Rahman $\mathrm{G} \mathrm{A}$ et $\mathrm{al}^{1}$, CLU are equal in both sexes. In present study CLU are more common in males (72\%) than in females $(28 \%)$.

According to Kahle B. et $\mathrm{al}^{5}$., $65.2 \%$ of leg ulcers are due to vascular etiology and among which, venous leg ulcers dominates the differential diagnosis, accounting for up to $47.6 \%$ of the cases. Arterial diseases account for $17.6 \%$, most others are due to neuropathy or combination of both. In present study CLU with vascular etiology accounted for only $35 \%$ all, among which venous ulcers were $26 \%$ and arterial ulcers $9 \%$. CLU associated with diabetes accounted for nearly $34 \%$, traumatic ulcers $16 \%$, malignant ulcers $5 \%$ and other ulcers for $7 \%$.

Diabetic leg ulcers were more common in males 22 cases $(65 \%)$, more prevalent in patients above the age of 5 lyears and more often seen in left limb 18 cases(53\%). Western studies have classified diabetic ulcers as metabolic. The most important factors responsible for causation of ulcer in diabetes are the arterio-sclerotic lesions in large leg arteries and or neuropathy resulting in decreased sensation. If diabetic ulcers in present study were considered as vascular disorders rather than metabolic, the percentage of vascular ulcers in our study is about $69 \%$ comparable to the study by Vamsidhar.L et al ${ }^{6}$.

In the present study, ulcers in the gaiter zone were mostly caused by venous insufficiency $(80.8 \%)$ and ulcers in the foot below the line of shoes were mostly caused by arterial insufficiency (88.9\%) and or diabetes (82.4\%). As per studies done by Hansson Carita et $\mathrm{al}^{7}$ on leg and foot ulcers, ulcers below the line of shoe and feet are considered mostly to be caused by arterial insufficiency and or diabetes, whereas gaiter zone are mostly caused by venous insufficiency.

About $60 \%$ of patients in our study had ulcers in the foot only. This is rather high figure in comparison to Hansson's study which showed about only $30 \%$ of the ulcers in the foot. This is probably because of more number of diabetic, arterial and traumatic ulcers in our study.

Cornwall et $a l^{8}$., in his study had median age of all patients 50 years and $44 \%$ of the patients are below the age of 50 years and Callam M. J. study ${ }^{9}$ also the elderly are not the only population at risk. In his study ulceration began before the age of 40 years in $22 \%$ of the population studied.

Peripheral vascular diseases increase with age and are 7 times more frequent in 50 years old patients when compared to 20 years old ${ }^{7}$. In this study, arterial ulcers are found to be maximum in the age group of 51 \& above years.

In present study venous ulcers were found to be more common in the age group of 31 to 40 years, which is rather early when compared to western studies. This discrepancy is due to the fact that, our study group patients in the above age group belongs to the working class, which involved long hours of standing, and the ulcers they suffer from hamper their working capacity making them seek medical help early. Elastic crepe bandages are the treatment of choice for venous ulcers patients ${ }^{10}$. In present study all the 26 patients of venous ulcers wore for elastic crepe bandages and undergone local dressings and Bisgaard's line of management. Among 26 patients with varicose veins, 23 underwent surgery in form of Trendelenburg's operation, ligation and subfascial ligation. The mean time for ulcer healing was 16.4 days. 2 patients with deep vein thrombosis underwent skin grafting which healed in 9 days only.

Among 34 diabetic patients, 30 patients were managed with regular dressings, antibiotics, slough excision and or debridement along with anti-diabetic therapy. However, the 
mean healing time was 21.5 days in overall diabetic ulcers. Four patients underwent amputation and 12 patients underwent skin grafting which healed in average of 11 days.

In present study, ulcers secondary to trauma were noted in 16 patients, 6 of them were found to be anemic. The rest of the 10 patients had avulsive injury with some degree of skin loss. 9 patients out of the 16 underwent skin grafting. The mean healing time of these traumatic ulcers were 15 days. Those managed conservatively had a mean healing time of 20.6 days and those with skin grafts had a mean healing time of 11 days.

According to Rahman GA et $\mathrm{al}^{1}$, pseudomonas aeroginosa and staphylococcus aureus constituted the majority of isolates recovered from wound, accounting for $32.6 \%$ and $23.9 \%$.

In our study the organisms isolated from the wounds were in following order staphylococcus (31\%), streptococcus (22\%), Klebsiella (14\%), Proteus (14\%), Pseudomonas (3\%), E.coli (3\%) and no growth in 13 cases (13\%).

\section{CONCLUSION}

The highest age incidence of leg and foot ulcers in this study was in the age group of 5 lyears and above $(45 \%)$. There was a marked male predominance of $72 \%$. Foot was the most commonly affected region. Venous ulcers were situated in the gaiter zone, diabetic ulcers were situated in the foot and arterial in the foot. Of malignant and other ulcers, $80 \%$ were situated in the foot and $20 \%$ in the leg. Staphylococcus was found to be the most common pathogen to be isolated from these ulcers.

4 patients with leg ulceration had infective gangrene of deeper tissues and they underwent amputation as a lifesaving procedure and 3 patients with malignant leg ulceration also underwent amputation. 26 patients with varicose veins underwent some form of operation. 9 among 16 patients with traumatic ulcers underwent skin grafting. The mean time for the ulcer to heal in patients, who were grafted was noted to be 9 days as against 22 days of those who did not undergo skin grafting.

As many factors lead to chronic lower leg ulceration, a comprehensive evaluation of patient, limb, and ulcer is required to determine etiology and to prepare an appropriate treatment plan. Management of patients with chronic ulcers has to be interdisciplinary and should include systematic assessment of the patient in order to ascertain the pathogenesis, definitive diagnosis, optimal treatment and educating patients on foot care and the importance of seeking early medical advice. With the availability of investigations, wide range of antibiotics and with ever improving dressing material, there is certainly a great improvement in treatment of chronic leg ulcers.

\section{REFERENCES}

1. Rahman GA, Adigun IA, Fadeyi A. Epidemiology, etiology, and treatment of chronic leg ulcer: Experience with sixty patients. Annals of African Medicine, January-March, 2010, Vol. 9, No. 1, pp. 1-4.

2. Shubhangi Vinayak Agale, "Chronic Leg Ulcers: Epidemiology, Aetiopathogenesis, and Management", Ulcers, vol. 2013, Article ID 413604, 9 pages, 2013. https://doi.org/10.1155/2013/413604.

3. R. V. González-Consuegra and J. Verdú, "Quality of life in people with venous leg ulcers: an integrative review," Journal of Advanced Nursing, 2011, vol. 67. no. 5, pp. 926-944.

4. Sasanka CS. Venous ulcers of the lower limb: Where do we stand?. Indian J Plast Surg 2012; 45:266-74.

5. B. Kahle, H. J. Hermanns, and G. Gallenkemper, "Evidence-based treatment of chronic leg ulcers," Deutsches Ärzteblatt International, 2011. vol. 108, no. 14, pp. 231-237.

6. Dr. Lanka Vamsidhar, Dr. Gaddala Penchalaiah and Annaladasu Srilekha. A clinical study of ulcers of the leg: A prospective comparative study. International Journal of Surgery Science. 2019; 3(3): 325-329. DOI: https://doi.org/10.33545/surgery.2019.v3.i3f.189

7. Hansson Carita, Studies on Leg and Foot Ulcers, Stockholm, Acta Derm
Venereol, 1988; 45

8. Cornwall JV, Dore CJ et al. Leg ulcers - Epidemiology and Etiology, Br J Surg 1986; 73:693-696

9. Callam MJ et al. Chronic Ulcers of the Leg: Clinical History, Br Med J. 1987; 294:1389-91

10. Rightor M, Myers MB, Cherry G, Relationship Between Oedema and Healing Rate of Stasis Ulcers of the Leg, Am J Surg, 124: 666-668. 